\title{
A indução de novas paisagens culturais ribeirinhas através do festejo de Nossa Senhora de Guadalupe, Fonte Boa (AM)
}

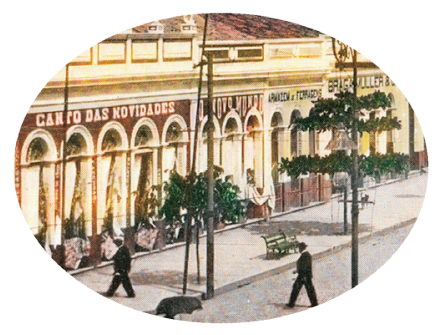

Yomarley Lopes Holanda*

\section{Resumo}

$\mathrm{Na}$ Amazônia mística, o caboclo da beira do rio desenvolveu mecanismos de criação e recriação dos espaços comunitários através de sua cultura. A igreja matriz, a praça, as procissões, os leilões, as festas dançantes, são caracteres dos festejos interioranos. No caso de Fonte Boa, o festejo da padroeira Nossa Senhora de Guadalupe é um desses momentos em que o grupo religioso age sobre o espaço, transformando-o, sacralizando-o, delimitando territórios com base nos seus pressupostos de existência. A discussão deste artigo envereda pelos conceitos de espacialidade e paisagem cultural na tentativa de compreender este evento, na aparência comum como tantos outros no Amazonas, e por isso mesmo diferente em seus princípios, em sua dinâmica.

Palavras-chaves: Festa; espaço; cultura.

\begin{abstract}
This In the mystical Amazon, the caboclo the brink of the river developed mechanisms for creation and recreation of communal spaces through their culture. The mother church, the square, the processions, the auctions, the festival dancing, the characters are population from rural areas celebrations. In the case of Good Source, the festival's patron saint Our Lady of Guadalupe is
\end{abstract}

\footnotetext{
* Licenciado em História pela UEA e mestrando em Sociedade e Cultura na Amazônia pela UFAM. E-mail: yomarleylopes@hotmail.com.
} 
one of those moments when the religious group acting on space, transforming it, make sacred, delimiting territories based on assumptions of its existence. The discussion of this article walks by the concepts of spatial and cultural landscape in trying to understand this event, common in appearance like many others in Arizona, and therefore different in its principles in its dynamics.

Keywords: Festival; space; culture.

\section{Introdução}

As análises apresentadas neste artigo são frutos da construção de minha dissertação de mestrado em Sociedade e Cultura na Amazônia, pela Universidade Federal do Amazonas. Tratam-se de estudos preliminares desenvolvidos na cidade de Fonte Boa, interior do Amazonas, localizada na região do Alto Solimões, aproximadamente $665 \mathrm{Km}$ de Manaus, onde participamos e pesquisamos o festejo de Nossa Senhora de Guadalupe, padroeira local, comemorado nos primeiros dias do mês de dezembro (4 a 12). A festa religiosa em comunidades ribeirinhas, no caso de Fonte Boa, constitui acontecimento ligado ao universo mental do grupo, capaz de promover mudanças na estrutura espacial da comunidade. Tal manifestação representa momento de identidade do grupo interiorano, acontecimento que possui seu próprio modo de ser realizado, refletindo a maneira pela qual o grupo estabelece sua vida.

Essencialmente católica, a cidade de Fonte Boa, assim qual a grande maioria das localidades amazônicas, cresceu e se desenvolveu ao redor da igreja matriz. Segundo Lisboa (1998) e Lins (2004), Fonte Boa foi fundada em 1689, a partir do território dos índios Jurimáguas, tendo como fundador o padre jesuíta Samuel Fritz, a serviço da Espanha. Com a expulsão dos jesuítas, a antiga missão de Nuestra Señora de Las Nieves de Los Jurimáguas, passou a ser administrada pela ordem dos Carmelitas portugueses, agora com o nome de aldeia de Taracuatíua, que significa "lugar de muita formiga", dada às condições de abandono a qual a antiga Missão foi relegada. De acordo com Lisboa (1998) embora existam poucos documentos sobre a educação colonial no Amazonas e, por sua vez, em Fonte Boa, pode-se verificar que todo o trabalho educacional foi voltado para o lado religioso. $\mathrm{Na}$ realidade, “o ensino na Amazônia voltou-se sempre para o adestramento indígena e 
sua deculturação. A catequese misturava a pregação da fé com a dominação política” (p. 39). Nesse período, somente os fiéis à Coroa Portuguesa ficavam encarregados de aldear os índios, por isso os missionários de Monte Carlo foram os pioneiros da história da educação no município estudado. Os pilares da educação na cidade de Fonte Boa foram implantados pelos missionários, e consistia no aldeamento indígena, na tentativa de unificar os diversos dialetos autóctones existentes em uma só língua. Todavia, somente no século XX, isto pôde acontecer, quando o primeiro vigário da paróquia local concluiu o trabalho de unificação das línguas, publicando uma gramática da Língua Geral (Nhengatú).

A breve contextualização histórica se fez necessária para mostrar os profundos traços de religiosidade do povo fonteboense que, desde os seus primórdios, passando pelo processo educacional, sempre foram norteados pelos princípios católicos. O que condicionou a comunidade religiosa à estruturação dos espaços com base no seu modo de "ver" o mundo e a vida. Foi justamente a cultura do grupo social cristão que modificou o espaço da cidade, quando em meados dos anos 80 a erosão provocada pela correnteza do rio Solimões ameaçava destruir a igreja matriz, então a comunidade resolveu "mudar" a igreja da frente da cidade para um lugar mais seguro e central. Os festejos se intensificaram por esta razão, com vistas à angariar fundos para a construção da nova igreja, maior, mais imponente, onde ao seu redor pudesse ser realizado o festejo da santa homenageada, onde o grupo se tornasse mais coeso e forte, numa clara demonstração de poder, mesmo contra as forças da natureza. A nova igreja matriz foi construída num lugar privilegiado, em frente à praça central (também chamada de praça Nossa Senhora de Guadalupe), lugar próximo às casas noturnas da cidade, bares, jogos, lojas, enfim, ambientes comuns durante todo o ano, exceto dezembro quando são revestidos e congregados pela sacralização por parte do grupo religioso local. Percebe-se que a paisagem natural ou mesmo a paisagem humana comum da cidade é transformada em paisagem religiosa no mês de dezembro, graças ao festejo da padroeira.

Historicamente a Amazônia é palco de interações e integrações do ponto de vista cultural, onde povos das mais variadas línguas e tradições constroem, pacifica ou belicamente, as suas relações entre si e com a natureza circundante. Benchimol (1999) nos lembra que, dentro deste quadro de "mistura", 
merecem destaque os povos indígenas, primeiros habitantes da Amazônia que edificaram, segundo Porro (1995) verdadeiras e complexas “civilizações" nas várzeas e terras-firme da região, deixando para a posteridade um rico legado cultural que vai desde hábitos até o universo mítico-lendário incorporado pelo folclore amazônico; os europeus que integraram ao contexto amazônico suas crenças ibéricas como os reisados, por exemplo, além da intensa religiosidade; e o negro, que para alguns pesquisadores não teve papel preponderante na conformação de uma "civilização cabocla", mas que aos poucos, pela luz de trabalhos inovadores (como "Os senhores dos rios" de Mary Del Priore e Flávio Gomes, por exemplo), vai entrando na história local como componente essencial da cultura amazônica, seja pelo suor e sangue, seja pelas danças e batuques assimilados por nossas festas.

As festas amazônicas, como tantas outras, religiosas ou não, são episódios onde as pessoas se reúnem e delas saem fortalecidas. Na festa, a sociedade comunga consigo mesma, atua como mecanismo catalizador das emoções, criatividade e participabilidade apoiada na construção coletiva. Essas festas comunitárias ocupam um lugar privilegiado na cultura brasileira. Seu forte apelo aos sentidos atrai e envolve tanto a comunidade quanto os visitantes e admiradores. Nas festas, por todo o Brasil, o jogo de cores, os ritmos. As toadas, os bailados e as comidas se multiplicam e encantam os que dela participam, criando um envolvimento que, de certa forma, dilui barreiras e fronteiras entre sagrado e profano, rico e pobre, brancos e mulatos. Podese dizer que, a despeito da modernidade, as festas crescem, se multiplicam e ganham visibilidade.

O professor José Aldemir no seu livro "Manaus: 1920 - 1967, a cidade doce e dura em excesso" trata de maneira poética sobre a festa que "representava a afirmação do cotidiano e era o reforço, não a ruptura como o modo de vida (...) fazia parte de um tempo, de um olhar de forma genérica, como se todos fossem iguais" (2003, p.149). Para ele a festa em Manaus era a apropriação da cidade por parte das populações locais, onde espaços e tempos destacavamse na paisagem. Todavia, como as festas em Fonte Boa, a festa retratada pelo professor José Aldemir foi "sistematizada, tornando-se lazer enquanto ruptura do cotidiano e imposição de novos valores. "Não é mais a festa, nem a atividade livre que se exerce por si mesma, é o espetáculo generalizado que se torna o espaço-tempo contínuo...” (OLIVEIRA, 2003, p. 149). 
Durkheim (1968, p. 547-548) também se ocupou do tema considerando que as festas, mesmo puramente laicas em sua origem, se concretizavam com ritos análogos às cerimônias religiosas, já que também aproximavam os indivíduos, movimentando as massas num estado de efervescência com gritos, cantos, músicas, expressão corporal incomum, tal qual acontecia nas celebrações religiosas. A religião, em especial o catolicismo e as festas mantêm uma tradição secular de convivência e conivência. Na modernidade, apesar de todas as transformações pelas quais os festejos, festas e festivais vêm passando, ainda existem comunidades que celebram popularmente os seus signos religiosos memoriais, geralmente ligados aos santos católicos.

Os grupos humanos da Amazônia formam uma individualidade que se expressa em vivências de cumplicidade com os seus ambientes naturais e sociais. Muitas dessas vivências são canalizadas em festas, festejos e festivais que, em suas diferentes modalidades e múltiplos significados e contextos, têm em comum o fato de criar um espaço essencial para fortalecer e nutrir a rede das relações sociais. Mauss (2003) diz que "é da natureza da sociedade que ela se exprima simbolicamente em seus costumes e em suas instituições” (p. 17), portanto, em nosso pensar, as festas interioranas do Amazonas possuem um sentido simbólico extremamente rico, evidenciado pela comunhão, participação coletiva, atividade espontânea que oportuniza a comunicação com o "outro". Em outras palavras, a festa "fala" sobre si mesma, sobre a cultura do lugar, sobre as relações tecidas no seu interior.

Os festejos interioranos "falam", a todo instante, da religiosidade ribeirinha, de sua cultura e de seu universo mental, uma vez que são movimentos que expressam os momentos de lazer, participabilidade e convivilidade que cria, reforça e nutre os laços sociais. A professora Marilene Corrêa afirma que "as festas são brincadeiras para quem as vive e sente como parte de sua sociabilidade, celebrações que reverenciam memórias perdidas que se resgatam (...) são signos, expressam sentidos do conjunto de simbolizações da cultura" (SILVA apud NOGUEIRA, 2008, p. 18). Ainda sobre a complexidade da manifestação festiva, Amaral (1998) postula que a festa é, conforme o contexto, capaz de celebrar, ironizar, sacralizar a experiência social e também individual. É também capaz de resolver, pelo menos no plano simbólico, as contradições sociais, servindo como "mediadora" entre as estruturas sociais, culturais e econômicas. 
Em artigo recente, o professor João de Jesus Paes Loureiro escreve sobre um fator importante de nossa "civilização cabocla: "na Amazônia também, como em todo o Brasil, o cidadão se expressa essencialmente pela emoção." (SOMANLU, 2002, p. 119). A religiosidade da população ribeirinha é uma das marcas de sua raiz colonizadora europeia, as festas de santos espalhadas por todo o interior são a prova disso. A igreja é sempre a construção central da cidade e ao seu redor desenvolve-se o todo social. Assim, igualmente, em Manaus, a festa religiosa teve papel importante na determinação da espacialidade da cidade de Fonte Boa. Sobre isso assim escreve o professor José Aldemir:

... a construção da capela antecedia à ocupação da área e em torno dela se erguia a praça, edificava-se a escola e o salão paroquial destinado a reuniões e festas. Este espaço, quase sempre localizado na área mais nobre, o que denota uma característica inerente à produção da cidade em todos os tempos em que o templo religioso ocupa lugar central e é considerado como um elemento forte na morfologia urbana (2003, p. 154).

Nesse sentido, torna-se claro que o aspecto sagrado é um elemento da produção espacial. "Os valores e crenças prevalecentes em qualquer tempo pode ser tão importantes na influência da produção do espaço urbano como fatores da natureza e da economia." (ROSENDAHL apud OLIVEIRA, 2003, p. 154).

Assim, os festejos de santos católicos merecem destaque pelo fato de representarem mudança, por modificarem o espaço e o tempo nas comunidades. Em algumas delas temos características mais visíveis dessas mudanças, como a construção de novas igrejas e a criação de espaços próprios para o santo padroeiro, caso específico da festa fonteboense.

Sacramentalismo cristão, devoção, pagamento de promessas, bingos, desfiles, comércio religioso, procissões e novenas, são características do festejo fonteboense, onde o ribeirinho participa ativamente como forma de agradecimento pelas graças alcançadas, seja a cura de uma grave enfermidade ou um ano próspero na pesca e na roça. São rituais que se repetem todos os anos e servem de catalizadores para o fortalecimento do grupo entre si e com a padroeira. Cada um dos momentos do festejo tem a sua própria razão de ser, 
possui a sua própria história. Desse modo, a estrutura espacial estará vinculada ao universo da fé, o que refletirá de maneira concreta na forma pela qual a comunidade religiosa irá estabelecer-se no espaço.

As formas de organização do espaço são dadas a partir da estrutura simbólica do grupo religioso que legitima o evento, ou seja, é a cultura, as crenças, enfim, o modo de vida dessas pessoas que acaba refletindo diretamente na configuração socioespacial da cidade durante a realização do festejo da padroeira. A forma de organizar o espaço socialmente construído, torna realmente este espaço "especial", "sagrado". Na realidade a festa, enquanto manifestação religiosa é um elemento de indução da espacialidade, uma vez que "considera-se que não são apenas as pedras, as calçadas, os edifícios novos ou velhos e as ruas que dão forma e conteúdo as cidades, mas todas as dimensões da vida humana" (OLIVEIRA, 2003, p. 155). A vida social pulsa na construção do espaço do festejo em Fonte Boa, e esse pulsar torna-se um lugar privilegiado do "encontro", da delimitação de territórios, da vivência através do uso nas realizações festivas.

Sobre esta questão de "humanização" do lugar através da ação de determinados grupos e sua estrutura mental, Luis Boada (1991, p.88), observa que o espaço pode ser humanizado, ou seja, transformado num lugar diferenciado do restante, basta que para tanto ali sejam realizados ritos que deem conta de tal tarefa, o que, aliás, pode muito bem ser realizado através das festas populares. A realidade vivida pelo homem ribeirinho está ligada ao seu comportamento eminentemente religioso, e tal comportamento está arraigado ao seu modo de vida:

Todas as crenças religiosas conhecidas, sejam elas simples ou complexas, apresentam um mesmo caráter comum: supõem uma classificação das coisas, reais ou ideais, que os homens representam, em duas classes ou em dois gêneros opostos, designados geralmente bem, pelas palavras profano e sagrado (DURKHEIM, 1989, p. 68).

Isso ocorre de forma continua e complexa na cidade de Fonte Boa, espaços públicos são dominados por grupos sociais legitimadores das festas. A paróquia vende os terrenos próximos à igreja à época dos festejos da padroeira, aluga os "espaços" outrora naturais, inferindo aos mesmos uma 
"aura" especial, sacralizando-os e tornando-os "espaços culturais", onde o religioso é entendido como elemento imprescindível naquele momento, assim como o grupo legitimador do evento estará intimamente ligado a esse espaço, exercendo o controle sobre o mesmo, reconhecendo nele os seus signos, mesmo que já o tenha transformado em mercadoria.

Além dos espaços no entorno da igreja, as ruas e a praça central da cidade também recebem novos significados, novas funções "sacras" que as tornarão, pelo menos de forma efêmera, lugares "especiais" qualificados conforme o imaginário religioso do grupo católico, ambientes com novas qualidades durante o festejo, mas que voltarão à normalidade tão logo se encerre as festividades.

Grande parte das festas, no seu momento de ocorrência, simplesmente fornecem nova função às formas espaciais prévias que dispõem para a sua realização (ponto central): rua, praças etc. mas, tão logo cesse o período ou momento extraordinário, tais formas retornam a sua função habitual (MAIA, 1999, p. 204).

As procissões tornam as ruas da cidade "sagradas", momentaneamente, os leilões e bingos para angariar fundos para a Paróquia transformam a praça central num lugar "religioso", até o comércio realizado por marreteiros nas áreas adjacentes da igreja, pelo fato de localizarem-se em lugares vendidos ou alugados pela paróquia, também tornam-se extraordinários, culturalmente modificados pela crença do grupo católico, não mais um lugar comum, mas um "espaço" único, com uma função previamente estabelecida pela comunidade cristã.

O espaço, não se trata somente de uma relação concreta, física, com ele, feita de práticas e de deslocamentos, ou de uma fenomenologia do espaço vivido, mas de um imaginário no qual entram os estereótipos da civilização e os valores ligados à identidade e à diferenciação social (RIVIÈRE, 1999, p. 59).

A comunidade ribeirinha fonteboense mantém intensos laços com o seu ambiente natural, pois vive o seu espaço, comungando de diversas maneiras 
com as matas e com as águas. Essa comunhão se dá através da sua cultura, crenças e religiosidade que, por sua vez, agem como elementos que promovem as modificações na paisagem natural, isto é, a ação humana embasada no imaginário do grupo, cria e recria novos espaços, ou melhor a fé, os mitos e as crendices do povo fonteboense, tornam-se aspectos constituintes deste espaço humanamente construído. Retomemos a discussão realizada anteriormente pelo professor José Aldemir quando esclarece que não só as pedras, ruas e calçadas formam o espaço, mas a ação humana através de sua cultura.

Aliás, os estudos da paisagem perpassaram os debates teóricos da Geografia Clássica, culminando com o surgimento do conceito de paisagem geográfica, onde os elementos do espaço passaram a ser vistos como frutos da ação humana sobre a natureza. Segundo Rosendahl (2001, p. 27) “o impacto da religião na paisagem não está limitada somente às características visíveis, tais como locais de culto (...), mas também na experiência da fé que nos fornecem símbolos e mensagens...". A chamada paisagem cultural conceituada por Sauer (1998) aparece como "modelada a partir de uma paisagem natural por um grupo cultural. A cultura é o agente, a área natural é o meio, a paisagem cultural é o resultado.” (p. 59).

Assim, em Fonte Boa, comunidade ribeirinha do Alto Solimões, o caboclo cria e recria os espaços conforme a sua cultura, cultura esta intensamente marcada pela religiosidade. Sua vivência relacional com as águas e com as matas proporciona-lhe percepções que moldam seus ambientes naturais. A palafita na beira do rio ou a casa na cidade, os igarapés ou as ruas, a imagem da santa carregada no andor ou a igreja, a procissão fluvial, lugares, paisagens marcadas pelo grupo que as vive, construções de uma dinâmica espacial rica e complexa norteada pela devoção, fé e cosmovisão mestiça.

\section{Referências}

BENCHIMOL, Samuel. Amazônia: formação social e cultural.Manaus: Ed. Valer, 1999.BOADA, Luis. O espaço recriado. São Paulo: Nobel, 1991.

DURKHEIM, Émile. As formas elementares de vida religiosa. São Paulo: Ed. Paulinas, 1989. 
- As regras do método sociológico. São Paulo: Companhia Nacional, 1968.

LISBOA, Humberto. Fonte Boa: chão de heróis e fanáticos. Fonte Boa: Ed. N.Sra. de Guadalupe, 1998.

LINS, Eylan. Fonte Boa: terra de bons frutos. Manaus: Imprensa Oficial, 2004. MAIA, Carlos Eduardo Santos. Ensaio interpretativo da dimensão espacial das festas populares: proposições sobre festas brasileiras. In: Manifestações da Cultura no espaço. Organizado por CORRÊA, Roberto Lobato, ROSENDAHL, Zeny. Rio de Janeiro: EDUERJ, 1999.

MAUSS, Marcel. Sociologia e Antropologia. São Paulo: Cosac \& Naif, 2003.

NOGUEIRA, Wilson. Festas amarônicas. Manaus: Ed. Valer, 2008.

OLIVEIRA, José Aldemir de. Manaus - 1920-1967: a cidade doce e dura em excesso. Manaus: Valer, 2003.

RIVIÈRE, Claude. Representação do espaço na peregrinação africana tradicional. In: Espaço e Cultura, UERJ - RJ. n. ${ }^{\circ}$ 7, p. 59-67. Jan-Jun, 1999.

ROSENDAHL, Zeny. Hieropólis: O sagrado e o urbano. Rio de Janeiro: EDUERJ, 2001.

SAUER, Carl. A morfologia da Paisagem. In: Paisagem, Tempo e Cultura. Organizado por CORREAA, Roberto Lobato, ROSENDAHL, Zeny. Rio de Janeiro: EDUERJ, 1998.

SOMANLU. Revista de Estudos Amazônicos. Publicação do Programa de Pós-Graduação em Natureza e Cultura na Amazônia, da Universidade do Amazonas. Ano II, n. ' 2: edição especial - Manaus: Edua, 2002. 